\title{
Interactive comment on "Using isotopes to understand evaporation, moisture stress and re-wetting in catchment forest and grassland soils of the summer drought of 2018" by Lukas Kleine et al.
}

\section{Anonymous Referee \#1}

Received and published: 3 April 2020

\section{General comments}

In the manuscript entitled 'Using isotopes to understand evaporation, moisture stress and re-wetting in catchment forest and grassland soils of the summer drought of 2018' the question is addressed, how the drought 2018 affected two different land-use/soil community sites in a catchment in NE Germany. The two plot sites were monitored during a period of water stress, when the catchment could no longer sustain blue water fluxes (e.g. stream flow) or green water needs (e.g. crop production), and the subsequent recovery.

Printer-friendly version

Discussion paper 
Ecosystem response to this climatic anomaly is investigated by using water stable isotope data of precipitation and throughfall, stream-, groundwater and especially from soil water profiles. Monthly soil profile samples in 6 different depths down to $1 \mathrm{~m}$ under two different land-use types were taken from September 2018 to February 2019. Soil water isotopes were analysed using direct vapor equilibration laser spectrometry (DVE-LS). These data were used to estimate mean transit times (MTT) in the soils at the different depths as well as young water fractions, using a fitted sine-wave method. Based on collected meteorological and sap flow data ET-pot was calculated. Soil moisture was monitored in three different depths at both sites. Drought severity was quantified with the SPI, based on long-term precipitation data from the DWD.

It could be shown that the forest soils were dominated by rapid young water fluxes after rainfall events whereas the grassland soils were more retentive and dominated by older water. It is concluded that implications for blue and green water management should be investigated in a greater range of representative vegetation/ soil units and that further research efforts on climate change and management adaptations in the critical zone of drought sensitive ecosystems is needed.

Overall, the manuscript is well structured and nicely written.

The topic fits well to the scope of the journal and appears to be of interest for the readers; I only suggest moderate revisions prior to acceptance and publication in Hydrology and Earth System Sciences.

Specific comments

Title

Please add which isotopes were investigated, either 'water stable isotopes' or 'stable isotopes (d18-O, d2-H)'.

Evaporation or Evapotranspiration?

Printer-friendly version

Discussion paper

L. 4 
Please add 'water' before ". . .stable isotopes to..."

L. 47

Compared to e.g. soil moisture probes, laser absorption spectroscopy is not really "inexpensive". . I I wouldn't go too deep into the history of stable isotope measurement techniques, but it could be added that compared to traditional mass spec. techniques, laser absorption spectroscopy is relatively inexpensive. Mentioning that the invention of laser absorption spectroscopy has facilitated several new techniques in the last ten years would also emphasise that your approach is relatively new.

\section{52}

Developed by whom? Not by Hendry et al., maybe they improved. Please delete "e.g.," in the brackets.

L. 60

Shift "To" to line 59 after "study"

L. 66

'located' instead of "based"

L. 123

Throughfall was sampled as well at $1 \mathrm{~m}$ height? Which distance between the five gauges?

L. 131

blank is missing between "for" and "d2H"

L. 132

Please complete “. . from October 2018 to. ..”

Printer-friendly version

L. 143 
Please provide part-no. of sample bags

L. 146

Please insert 'gas' after "headspace"

L. 147

What kind of 'standards' were used?

L. 150

d-Excess should be introduced somewhere here.

L. 150-152

Method or results section?

L. 157

Please add 'oil' after "paraffin"

L. 171

Where can I see "young water" in figure 2?

L. 171-172

Method or results section?

L. 213

One would always expect slightly evaporated signals in throughfall (enriched in heavy isotopes) compared to precipitation. In your study it is opposite (Fig. 4, Table 4), this seems to be in contradiction to your soil profile data (Table 5). Please elaborate on this.

L. 223 
Please delete one of the "in" before "Figure 4"

\section{225}

Is the sample number of precipitation really higher than throughfall? According to Table 4: precipitation (68), throughfall (136). Please clarify.

L. 232

I like the heat map (Figure 5), but you could think about providing a figure for each site with the soil profile isotope data as supplemental material.

\section{L. $238-240$}

Not clear what you mean, please rephrase.

L. 259

'upper' instead of "top"

L. 260

Please insert 'the upper' before "three of the..."

L. 289

Insight 'into' instead of "in"

L. 316

Please replace "soils" by 'soil layers'.

L. 324

Stick to "ðiđđł-values" to be consistent with L. 323 and Table 6.

L. 338

Please insert 'in' or 'reported from' before “... the previous winter”. 
L. 342

'storage,' instead of "stores"

L. 356-357

“. . .urgency with the by..." ??? Please rephrase.

Interactive

comment

L. 369

“. . headwater. .." is 'catchment' missing?

L. 376

Please add 'the two' between "between" and "sites"

L. 378

Please insert ' 1 ' before "year old)"

Fig. 1

There is enough space to put the overview beneath the detailed maps - makes the layout of the figure a bit clearer.

Right part: please replace "Landuse" by 'Soils'

Fig. 3

Legend: ' $h$ ' is missing in "Troughfall"

Fig. 5

Please label forest and grassland.

Table 4

Printer-friendly version

Deltas are missing in header

Discussion paper

Are 5th and 95th percentile of d18-O identical for precipitation and throughfall? Stream: 
5th and 95th percentile of d18-O both -8.6? Please double-check.

Table 5

Caption: 'soil water isotope samples' instead of "soil isotopes samples"

Global changes

I would prefer "and" instead of "\&" (e.g. I. 62, 112, 136)

please change "stable water isotopes" to 'water stable isotopes'

check '-' vs. '-' throughout the manuscript (e.g. L. 287, L. 291)

Please also note the supplement to this comment:

https://www.hydrol-earth-syst-sci-discuss.net/hess-2020-81/hess-2020-81-RC1supplement.pdf

Interactive comment on Hydrol. Earth Syst. Sci. Discuss., https://doi.org/10.5194/hess-2020$81,2020$. 